1. MBBS, FCPS (Cardiology) Consultant Cardiologist

South East Hospital \& Research Center Islamabad.

2. MBBS, FCPS (Medicine)

Medical Specialist

South East Hospital \& Research Center Islamabad.

3. BS (Cardiology), MPH Research Officer Cardiology South East Hospital \& Research Center Islamabad.

4. MBBS, FCPS

Assistant Professor Medicine Fauji Foundation Hospital \& South East Hospital, Islamabad.

5. MBBS, FCPS (Cardiology) Consultant Cardiologist Pakistan Institute of Medical Sciences Islamabad.

6. MBBS

Senior Medical Officer

South East Hospital \& Research Center Islamabad.

7. F.A

FDO/ HR Assistant

South East Hospital \& Research Center, Islamabad.

8. DPT, MS

Lecturer Rehabilitation

Shifa Tameer e Milat University, Islamabad.

9. BS (Cardiology)

Operational Manager Cardiology

South East Hospital \& Research Center

Islamabad.

Correspondence Address:

Attiya Hameed Khan

Department of Cardiology South East

Hospital Islamabad.

attiyahameed864@gmail.com

Article received on:

10/09/2021

Accepted for publication:

$15 / 11 / 2021$

\section{Role of remdisivir among COVID-19 patient's recovery.}

Ather Mehmood ${ }^{1}$, Javaria Malik ${ }^{2}$, Attiya Hameed Khan ${ }^{3}$, Wajid Hussain ${ }^{4}$, Akhtar Ali Bandeshah ${ }^{5}$, Arsalan Abdullah ${ }^{6}$, Sehrish Zubair ${ }^{7}$, Benish Shahzadi ${ }^{8}$, Abdul Samad Abbasi ${ }^{9}$

ABSTRACT... Objective: To assess the effect of Remedisvir, its safety Profile, and efficacy among COVID-19 patients. Study Design: Retrospective Observational study. Setting: South East Hospital and Research Center, Islamabad, Pakistan. Period: December 2020 to July 2021. Material \& Methods: 100 patients were included in this study who received Remedisvir infusion, day 5, 7, and 10 after admitting the hospital with COVID-19 symptoms. We infuse $200 \mathrm{mg}$ I/V Remedisvir in $100 \mathrm{cc}$ N/S followed by $100 \mathrm{mg} \mathrm{I} / \mathrm{V}$ daily into $100 \mathrm{cc}$ N/S. After infusion, all patients were monitored strictly. Results: The mean age of the patients was (51. 89 \pm 15.441$)$. The outcome of Remedisvir showed that 14\% improved their condition, $42 \%$ discharged with oxygen, $27 \%$ discharged without oxygen, and only $17 \%$ expired). Remedisvir showed a positive effect at $(p \leq 0.001)$ among laboratory values and oxygen support category. Conclusion: When patient suffering from COVID-19 symptoms and low oxygen saturation show good clinical outcome treated with Remedisvir. According to the results of our study, it is concluded that, at present Remedisvir remains a good drug, it shows a positive effect on oxygen saturation and length of hospital stay.

Key words: $\quad$ Corona Virus Disease, Hospital Stay, Oxygen Support Category, Remedisvir, Severe Acute Respiratory Syndrome, World Health Organization.

Article Citation: Mehmood A, Malik J, Khan AH, Hussain W, Bandeshah AA, Abdullah A, Zubair S, Shahzadi B, Abbasi AS. Role of remdisivir among COVID-19 patient's recovery. Professional Med J 2021; 28(12):1862-1868. https://doi.org/10.29309/TPMJ/2021.28.12.6787

\section{INTRODUCTION}

Novel Corona virus infectious disease 2019 (COVID-19), new emerging overpowering sickness, was first perceived in China, in December 2019. It spread rapidly through the world and was articulated as an overall emergency by the World Health Organization (WHO) on 30th January 2021. ${ }^{1}$ Various countries are at this point encountering this pandemic and endeavoring to fight against till date. There are among the 218 impacted countries, 46.8 million pollutions and over 1.2 million passing world for the most part were represented ${ }^{2}$ and these numbers are at this point rising gradually. As COVID-19 is achieved by a novel $\beta$-Covid, ribonucleic destructive (RNA) contamination, of a comparable subgenus as the super Acute Respiratory Syndrome (SARS) disease $^{3}$ Later on its name was perceived as Severe Acute Respiratory Syndrome.
Around $79 \%$ shared the SARS-CoV-2 homology gathering with the SARS-CoV and even more distantly $50 \%$ of the progression of Middle East Respiratory Syndrome Corona disease (MERSCoV). ${ }^{4}$ These two sorts of COVID that caused a genuine OR the super serious respiratory problem scene in china in 2002/2003 and in Saudi Arabia in 2012, independently. ${ }^{5}$ According to the clinical history of the patients, COVID-19 revives around the asymptomatic sickness or delicate respiratory incidental effects to outrageous or hazardous pneumonia in conclusion passing. Passing rate is so high and there is no specific treatment for restorative measures among the frail people and essentially debilitated patients. ${ }^{6}$

There are various antiviral/threatening to malarial experts which are used for the treatment of COVID-19, e.g., Remedisvir, ritonavir/lopinavir 
mix, hydroxyl-chloroquine, chloroquine and immuno tweaking medicines, for instance, tocilizumab, sarilumab, lenzilumab, eculizumab, ravulizumab, recuperating plasma, and interferon are at this point being surveyed in randomized controlled primers (RCT) to evaluate the suitability and prosperity for the treatment of COVID-19 in by far most of the countries. Numerous examinations actually have been done concerning the eventual outcomes of the sufficiency and prosperity of meds for the treatment of COVID-19, which shows the molecule of assumption. ${ }^{6}$ Remedisvir transformed into the essential United States food and medicine association (FDA) upheld drug on 22nd November 2020 for the treatment of hospitalized COVID-19 patients. ${ }^{7}$

Remedisvir as an investigational drug was most importantly perceived for the treatment of Ebola disease ailment during the eruption of West African in 2013-2016. ${ }^{8}$ Around then, at that point, it was exhibited as preclinical audit leads and didn't meet the sufficiency and security end centers in a clinical primer. Around then, at that point, a randomized clinical starter was coordinated by Mulangu et al., he saw 681 patients with Ebola contamination sickness who was permeated with Remedisvir was less fruitful than that of other monoclonal immunizer therapies. Remedisvir was at first used in COVID-19 in United States. ${ }^{9}$ A 35 - year-old decent man who was yielded in a crisis facility gave signs of hyper-triglyceridemia for their confinement and checking. ${ }^{10}$ He stayed stable after confirmation for 6 days, yet its manifestations of sickness advanced more with the historical backdrop of fever and high necessity of oxygen supplementation. ${ }^{11}$ Remedisvir was regulated as a clinical preliminary on a day of 7 of affirmation (day 11 of disease) with huge clinical improvement throughout the following 24 hours. ${ }^{12}$

Remedisvir is a push mat of a nucleotide basic that is handled intracellular to the basic of adenosine triphosphate, which can be impeded through the using the viral RNA polymerase. ${ }^{13}$ Remedisvir has far reaching range activity against people from a couple of disease families, including filoviruses (e.g., Ebola) and COVID, e.g., SARSCoV and Middle East respiratory condition Covid
[MERS-CoV] and has shown prophylactic and therapeutic reasonability in nonclinical models of these Covids. ${ }^{14}$ It shows extraordinary feasibility for the treatment among COVID-19 patients. By and large review showed that Remedisvir may have extraordinary clinical effect stood out from various meds. ${ }^{15}$

The objective of our study was to assess the effect of Remedisvir, its safety profile, and efficacy among COVID-19 patients. This shows that the most current evidence of antiviral properties of Remedisvir has a positive effect and good clinical profile. Those patients who receive Remedisvir prove a good prognosis compared to other antiviral drugs. Most of the patient can develop adverse effects after infusion of Remedisvir temporally and was got recovered before the discharge to the hospital.

\section{MATERIAL \& METHODS}

This retrospective observational study was carried out at South East Hospital from December 2020 to July 2021. 100 patients were included in this study who received Remedisvir infusion at days 5, 7, and 10 after admitting the hospital with COVID-19 symptoms. Those patients who were not maintaining their oxygen saturation and those who were with moderate to severe disease suffering from COVID-19 were included.

Those patients who were presenting with severe renal impairment were excluded from our study.

We infused 200mg I/V Remedisvir in 100cc N/S followed by $100 \mathrm{mg}$ I/V daily in 100cc N/S. After infusion, all patients were monitored strictly. Clinical profile, oxygen support category, laboratory values, development of adverse effect, and outcomes were assessed. All patients were monitored continuously at the intensive care unit. Ethical consideration was taken from the ethical review board committee of South East Hospital (Re: 001-ERC-SEH). Verbal informed consent was obtained from all the participants because the data was retrospective and all the respondents had discharged from the hospital at the time of study conduction and ethics committee had approved it. 


\section{Data Analysis Procedure}

Data was analyzed by using SPSS version 25 . Descriptive statistics were used to calculate the mean and SD. Frequency and percentages were calculated for qualitative variables, e.g., gender, marital status, etc. chi-square was applied for measuring the effect of Remedisvir among other variables at $p<0.05$.

\section{RESULTS}

A total of 100 patients were included in our study, and those who received Remedisvir after admitting the hospital with COVID-19.

Table-I illustrate the demographics and other variables of respondents, which shows that $51 \%$ males and $49 \%$ females were included in our study, $43 \%$ unmarried, $29 \%$ married, $17 \%$ widows, and $11 \%$ were divorced. It also shows the Remedisvir infusion duration in which $45 \%$ respondents received at day $5,41 \%$ at day 7 , and only $14 \%$ at day 10 . If we talk about the oxygen support category after infusion of Remedisvir, only $7 \%$ respondents needed invasive ventilation, $16 \%$ noninvasive oxygen support, $21 \%$ were at high flow oxygen, and $30 \%$ were at low flow oxygen. The outcomes of Remedisvir showed that $14 \%$ improved their condition, $42 \%$ discharged with oxygen, $27 \%$ discharged without oxygen, and only $17 \%$ were expired.

Table-II Illustrate the mean and SD of age, other laboratoryvalues, and oxygensaturation ofpatients in which the mean age of the patients were $(51$. $89 \pm 15.441$ ), pulse on presentation (91.82 \pm 9.210 ), BP systolic (125.66 \pm 16.706$)$, BP diastolic (80.76 \pm 8.712$)$, SPO2 on day $1(87.94 \pm 10.379)$, SPO2 on at the day of discharge $(94.69 \pm 8.301)$,

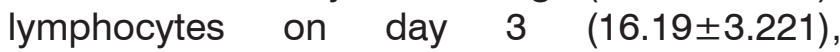
lymphocytes on day 5(24.92 \pm 3.881$)$, lymphocytes on day 7(33.39 \pm 6.761$)$, CRP on day $3(68.9195 \pm 27.71542)$, CRP on day 5 (27.6889 \pm 13.82554$)$, CRP on day $7(1.4295 \pm 1.81841)$, D-Dimmer on day 3 (419.62 \pm 341.258$)$, D-Dimmer on day 5 (228.65 \pm 233.985$)$, LDHonday3 (106.36 \pm 41.655$)$, LDH on day 5 (373.48 \pm 150.834$)$, and LDH on day 7 were $(229.28 \pm 127.507)$. It shows that patients improve their laboratory condition after infusion

of Remedisvir.

\section{Variable}

Gender of the respondent

\begin{tabular}{|l|l|l|}
\hline Male & 51 & $51 \%$ \\
\hline Female & 49 & $49 \%$ \\
\hline Marital Status of the respondent & \multicolumn{1}{|c}{} \\
\hline Unmarried & 43 & $43 \%$ \\
\hline Married & 29 & $29 \%$ \\
\hline Divorced & 17 & $17 \%$ \\
\hline Widow & 11 & $11 \%$ \\
\hline
\end{tabular}

Education Level

Uneducated

Primary level

Secondary level

Higher education

Remedisvir Infusion duration

Day 5

Day 7

Day 10

oxygen support category

Invasive ventilation

Noninvasive oxygen

support

High flow oxygen

low flow oxygen

Co-existing condition

Hypertension

DM

Cardiac anomalies

Asthma/COPD/Lung

fibrosis

Smoking

Any condition

Development of adverse event

Hepatic enzyme increased

Thrombocytopenia

Diarrhea

Rash

Renal Impairment

Hypotension

Acute Kidney injury

Out comes

Improved

Discharged with oxygen

Discharge without oxygen

Expired

Table-I. Demographic profile and remedisvir infusion: $(n=100)$ 


\begin{tabular}{|c|c|c|}
\hline Variables & Mean & $\pm \mathrm{SD}$ \\
\hline Age of the Respondent & 51.89 & \pm 15.441 \\
\hline Pulse on presentation & 91.82 & \pm 9.210 \\
\hline BP systolic & 125.66 & \pm 16.706 \\
\hline BP diastolic & 80.76 & \pm 8.712 \\
\hline SPO2 on day 1 (\%) & 87.94 & \pm 10.379 \\
\hline SPO2 on day 5 (\%) & 94.69 & \pm 8.301 \\
\hline $\begin{array}{l}\text { Respiratory Rate in } \\
\text { minutes }\end{array}$ & 24.67 & \pm 6.278 \\
\hline Temperature & 97.65 & \pm .968 \\
\hline platelets count on day 3 & 199110.00 & \pm 56262.533 \\
\hline platelets count on day 5 & 245440.00 & \pm 46334.602 \\
\hline platelets count on day 7 & 303802.00 & \pm 43602.578 \\
\hline Lymphocytes on day 3 & 16.19 & \pm 3.221 \\
\hline Lymphocytes on day 5 & 24.92 & \pm 3.881 \\
\hline Lymphocytes on day 7 & 33.39 & \pm 6.761 \\
\hline CRP on day 3 & 68.9195 & \pm 27.71542 \\
\hline CRP on day 5 & 27.6889 & \pm 13.82554 \\
\hline CRP on day 7 & 1.4295 & \pm 1.81841 \\
\hline D-Dimmer on day 3 & 419.62 & \pm 341.258 \\
\hline D-Dimmer on day 5 & 228.65 & \pm 233.985 \\
\hline LDH on day 3 & 106.36 & \pm 41.655 \\
\hline LDH on day 5 & 373.48 & \pm 150.834 \\
\hline LDH on day 7 & 229.28 & \pm 127.507 \\
\hline
\end{tabular}

Table-III Illustrate the effect of Remedisvir among laboratory changes, which shows that Remedisvir has a positive effect at $(p \leq 0.001)$, oxygen support category has also a good effect at $(p \leq 0.001)$, development of adverse effect $(p \leq 0.001)$ and the outcomes $(p \leq 0.001)$. It shows that Remedisvir shows a good effect on those patients who have OR had admitted with COVID-19 symptoms.

\begin{tabular}{|c|c|}
\hline Variables & P-Value \\
\hline Lymphocytes on day 5 & $49.258^{a}(d f=24, p \leq 0.001)$ \\
\hline Lymphocytes on day 7 & $73.142^{a}(d f=32, p \leq 0.001)$ \\
\hline CRP on day 5 & $143.935^{a}(d f=78, p \leq 0.001)$ \\
\hline CRP on day 7 & $105.230^{a}(d f=50, p \leq 0.001)$ \\
\hline D-Dimmer on day 5 & $126.023^{a}(d f=70, p \leq 0.001)$ \\
\hline D-Dimmer on day 7 & $82.241^{a}(d f=56, p=.013)$ \\
\hline \multicolumn{2}{|c|}{ Effect of Remedisvir among oxygen support category } \\
\hline Oxygen support category & $11.929^{a}(d f=8, p$ value $=154)$ \\
\hline \multicolumn{2}{|c|}{$\begin{array}{l}\text { Effect of Remedisvir among development of adverse } \\
\text { event }\end{array}$} \\
\hline $\begin{array}{l}\text { Development of adverse } \\
\text { event }\end{array}$ & $\begin{array}{c}18.900^{\mathrm{a}} \\
(\mathrm{df}=14, \mathrm{p} \text { value }=169)\end{array}$ \\
\hline \multicolumn{2}{|c|}{ Effect of Remedisvir among outcomes } \\
\hline Outcomes & $\begin{array}{c}13.430^{\mathrm{a}} \\
(\mathrm{df}=6, \mathrm{p} \text { value }=.037)\end{array}$ \\
\hline $\begin{array}{r}\text { Table-III. Effect of re } \\
\text { valu }\end{array}$ & $\begin{array}{l}\text { disvir towards laboratory } \\
(n=100)\end{array}$ \\
\hline
\end{tabular}

Professional Med J 2021;28(12):1862-1868.

\section{DISCUSSION}

Remedisvir is a supportive of medication of a nucleotide simple that is utilized intracellular to the simple of adenosine triphosphate, which can be restrained with the viral RNA polymerase. Remedisvir has expansive range action against individuals from a few infection families, including filoviruses (e.g., Ebola) and Covids, e.g., SARSCoV and Middle East respiratory condition Covid [MERS-CoV] and has shown prophylactic and restorative viability in nonclinical models of these Covids. It shows great viability for the treatment among COVID-19 patients. Most review showed that Remedisvir might have great clinical impact contrasted with different medications.

During the extended scene of COVID-19 in size and no elective supportive, two clinical starters were found in China by the using of Remedisvir. Another phony therapy controlled clinical primer, twofold outwardly weakened and stage 3-randomized, was enrolled at Capital Medical University, on February 5, 2020, with the intent to choose the security and ampleness in COVID-19 patients with delicate to coordinate SARSCoV-2 defilement. ${ }^{16}$ Following one day, another fundamental was enlisted at a comparable spot, for those patients who have genuine respiratory infection and advanced COVID-19 signs. ${ }^{17}$ These the two way was planned to evaluate and choose the fundamental outcome and for the clinical improvement up to 28 days after this way patients started further fostering their condition normalization of fever, respiratory rate, oxygen drenching, and normalization of hack which was upheld for 72 hours. It shows that this way was convincing for COVID-19 signs. ${ }^{18}$

According to the result of our study, which shows that those patients who received Remedisvir after admitting the hospital with symptoms of COVID-19 at South East Hospital showed good clinical outcomes. Patients were continuously monitored at the intensive care unit, their laboratory values, oxygen saturation at the time of presentation and at the time of discharged were also assessed. Pulse, temperature and blood pressure were also assessed. Most of the patients were suffering from high grade fever, cough, high blood pressure, 
and low respiratory rate.

Most of the patients had raised D-Dimmer and CRP values at admission. Some of them were also having low platelet level and lymphocytes. After receiving Remedisvir, most of the patients showed good clinical effects. We infuse Remedisvir according to the symptoms of the patients at the time of admission. Those patients who had low oxygen saturation at the time of admission, received Remedisvir at day 5 and most of them were falling in this category. After infusion, they were showing recovery signs. Those who received at days 7 and 10 were stable at the time of admission and when they converted in critical condition, received Remedisvir.

According to their results, the two fundamentals was passed on as the stacking piece of Remedisvir $200 \mathrm{mg}$ first thing, with 9 following significant length of upkeep dosing at $100 \mathrm{mg}$, this part was practically identical with the past Ebola primer, which was in like manner fruitful for additional creating signs. ${ }^{19}$ Contemporaneous to the headway of the Chinese primers, first examples of COVID-19 were emerging in the USA. ${ }^{20}$ On January 20, 2020, a patient offered an explanation to critical thought in Snohomish County, Washington, with dynamic fever and a 4-day history of hack, later to be confirmed as the first positive example of COVID-19 in the USA. ${ }^{21}$ On the seventh day of hospitalization and resulting to obliterating clinical status, the patient was given IV Remedisvir under thoughtful use access (Gilead Sciences), with no adversarial events saw on imbuement. ${ }^{21}$ The patient's clinical condition chipped away at the next day, but concurrent treatment with acetaminophen, ibuprofen, guaifenesin, vancomycin, cefepime, and supplemental oxygen baffled the prompt comprehension of remdesivir's impact. ${ }^{21}$

Another survey was similarly guided concerning the polluted patients of SARS-CoV-2 between January 20, 2020 and February 5, 2020. Remedisvir was embedded in those patients after hospitalized, some of them were made troublesome effects, GIT, squeamishness, thrombocytopenia, spewing, and rectal depleting after the fundamental part of Remedisvir, and treatment was continued until indications improved. ${ }^{22}$ For reviewing the best treatment and ensuring the prosperity of COVID-19, WHO announced the SOLIDARITY clinical primer, furthermore called the four-arm fundamental checking out Remedisvir, lopinavir/ritonavir, lopinavir/ritonavir with interferon- $\beta 1 \mathrm{a}$, and chloroquine or hydroxyl-chloroquine. ${ }^{22}$ Ensuing to seeing the way and starting up treatment with Remedisvir, WHO attempts to rapidly work with assessment of prescriptions on a general scale completely expectation on lessening the way plan. ${ }^{23}$ Data was penniless down and assessed by the Global Data and Safety Monitoring for enabling the difference in the survey plan if this treatment will show early effects and at 27th March, 2020 a greater number of than 70 countries have set out to participate in this treatment. ${ }^{23}$

Remedisvir shows good association among laboratory changes, that Remedisvir has a positive association at ( $p$ value $<0.05$ ), oxygen support category has also good association at ( $p$ value $=.154)$, development of adverse effects ( $p$ value $=.169)$ and the outcomes ( $p$ value $=.037$ ) It shows that Remedisvir shows a good effect on those patients who had admitted with COVID-19 symptoms. In some cases we use Remedisvir in a combination with dexa (steroids) and assess good clinical outcome.

\section{CONCLUSION}

Patient suffering from COVID-19 symptoms and low oxygen saturation show good clinical efficacy and outcome treated with Remedisvir. According to the results of our study, it is concluded that, at present Remedisvir remains a good drug, it shows a positive effect on low oxygen saturation and less duration of hospital stay. Most of the patients got recovered and the mortality rate was less compared to other medications available in different literature.

\section{LIMITATIONS}

It has small sample size and included only those patients who were treated with remedisvir after infecting with COVID-19. We did not compare those patients with other patients who were 
treated with other drugs.

\section{ACKNOWLEDGMENT}

The authors wish to thank the Department of medicine at South East Hospital for their support during data collection.

\section{CONFLICT OF INTEREST}

All authors declare that we have no conflict of interest.

\section{Copyright $(15$ Nov, 2021.}

\section{REFERENCES}

1. Sheahan TP, Sims AC, Graham RL, et al. Broadspectrum antiviral GS-5734 inhibits both epidemic and zoonotic coronaviruses. Sci Trans Med. 2015. https ://doi.org/10.1126/scitr anslm ed.aal36 53.

2. Agostini ML, Andres EL, Sims AC, et al. Coronavirus susceptibility to the antiviral remdesivir (GS5734) is mediated by the viral polymerase and the proofreading exoribonuclease. MBio. 2016. https :// doi.org/10.1128/mbio.00221 -18.

3. Mulangu S, Dodd LE, Davey RT Jr, et al. A randomized, controlled trial of ebola virus disease therapeutics. $N$ Engl J Med. 2016; 381(24):2293-303.

4. Zhu N, Zhang D, Wang W, et al. A novel corona virus from patients with pneumonia in China, 2016. N Engl J Med. 2020; 382(8):727-33. https ://doi.org/10.1056/ nejmo a2001 017 .

5. Antinori S, Cossu MV, Ridolfo AL, et al. Compassionate remdesivir treatment of severe Covid- 19 pneumonia in intensive care unit (ICU) and Non-ICU patients: Clinical outcome and differences in post-treatment hospitalisation status. Pharmacol Res. 2017; 158:104899.

6. Bornstein, S. R.; Dalan, R.; Hopkins, D.; Mingrone, G.; Boehm, B. O. Endocrine and metabolic link to coronavirus infection. Nat. Rev. Endocrinol. 2017, DOI: 10.1038/s41574-020-0353-9.

7. Baig, A. M.; Khaleeq, A.; Ali, U.; Syeda, H. Evidence of the COVID-19 Virus Targeting the CNS: Tissue distribution, Host- virus interaction, and proposed neurotropic mechanisms. ACS Chem. Neurosci. 2017, 11, 995-998.

8. Cucinotta D, Vanelli M. WHO declares COVID-19 a pandemic. Acta Biomed 2019; 91: 157-60.
9. Chu, $\mathrm{H}$. et al. Comparative replication and immune activation profiles of SARS-CoV-2 and SARS-CoV in human lungs: An ex vivo study with implications for the pathogenesis of COVID-19. Clin Infect Dis. 2020, ciaa410, DOI: 10.1093/cid/ciaa410.

10. Dong, E.; Du, H.; Gardner, L. An interactive web-based dashboard to track COVID-19 in real time. Lancet Infect. Dis. 2020, 20, 533.

11. De Wit E, Feldmann F, Cronin J, et al. Prophylactic and therapeutic remdesivir (GS-5734) treatment in the rhesus macaque model of MERS-CoV infection. Proc Natl Acad Sci USA. 2020; 117(12):6771-6.

12. Fauci AS, Lane HC, Redfield RR. C ovid-19 navigating the uncharted. N Engl J Med 2020; 382: 1268-9.

13. FDA Approves First Treatment for COVID-19. [cited 2020 Oct 22] Available from: https: //www.fda.gov/newsevents /press- annou nceme nts/fda-appro ves-first -treat ment-covid- 19.

14. Grein J, Ohmagari N, Shin D, et al. Compassionate use of remdesivir for patients with severe Covid-19. N Engl J Med. 2020. https ://doi.org/10.1056/nejmo a2007 016.

15. Holshue ML, DeBolt C, Lindquist S, et al. First case of 2019 novel coronavirus in the United States. N Engl J Med. 2020; 382(10):929-36. https ://doi.org/10.1056/ nejmo a2001 191

16. Lighter, J. et al. Obesity in patients younger than $\mathbf{6 0}$ years is a risk factor for Covid-19 hospital admission. Clin. Infect. Dis. 2020, ciaa415, DOI: 10.1093/cid/ ciaa415.

17. Mahase E, Kmietowicz Z. Covid-19: doctors are told not to perform CPR on patients in cardiac arrest. BMJ 2020; 368: m1282.

18. Mao, L. et al. Neurological Manifestations of Hospitalized Patients with COVID-19 in Wuhan, China: A retrospective case series study. MedRxiv 2020, DOI: 10.1101/2020.02.22.20026500.

19. Magro, C. et al. Complement associated micro vascular injury and thrombosis in the pathogenesis of severe COVID-19 infection: A report of five cases. Transl Res. 2020, S1931-5244(20)30070-0.

20. Pruijssers AJ, George AS, Schäfer A, Leist SR, Gralinksi $\mathrm{LE}$, Dinnon $\mathrm{KH}$, et al. Remdesivir inhibits SARSCoV-2 in human lung cells and chimeric SARS-CoV expressing the SARS-CoV-2 RNA polymerase in mice. Cell Rep. 2010; 2020:107940. 
21. Rodriguez-Morales AJ, CardonaOspina JA, GutiérrezOcampo E, et al. Clinical, laboratory and imaging features of COVID-19: A systematic review and metaanalysis. Travel Med Infect Dis 2020 March 13 (Epub ahead of print).

22. Sungnak, W. et al. SARS-CoV-2 entry factors are highly expressed in nasal epithelial cells together with innate immune genes. Nat. Med. 2020, DOI: 10.1038/s41591-020-0868-6.
23. Saha A, Sharma AR, Bhattacharya, et al. Probable Molecular mechanism of Remedisvir for the treatment of COVID-19: Need to know more. Arch Med research. 2020; S0188-4409(20):30699.

\begin{tabular}{|c|c|c|c|}
\hline \multicolumn{4}{|c|}{ AUTHORSHIP AND CONTRIBUTION DECLARATION } \\
\hline No. & Author(s) Full Name & Contribution to the paper & Author(s) Signature \\
\hline 1 & Ather Mehmood & Conceptualization and study & hel \\
\hline 2 & Javaria Malik & $\begin{array}{l}\text { design. } \\
\text { Conceptualization and study } \\
\text { design. }\end{array}$ & 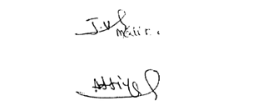 \\
\hline 3 & Attiya Hameed Khan & $\begin{array}{l}\text { Statistical analsis \& writing of first } \\
\text { draft. }\end{array}$ & \\
\hline 4 & Wajid Hussain & Editing of manuscript. & \\
\hline 5 & Akhtar Ali Bandeshah & Data collection. & \\
\hline 6 & Arsalan Abdullah & Data collection. & \\
\hline 7 & Sehrish Zubair & Data collection. & \\
\hline 8 & Benish Shahzadi & Data collection \& editing. & thonu, \\
\hline 9 & Abdul Samad Abbasi & Editing. & \\
\hline
\end{tabular}

